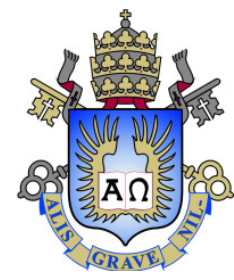

Bruno Costa Larrubia

\title{
A noção de consciência: ecos do cartesianismo e uma crítica a partir da Pragmática
}

\section{Dissertação de Mestrado}

Dissertação apresentada ao Programa de Pós-graduação em Psicologia da Pontifícia Universidade Católica do Rio de Janeiro (PUC-Rio), como requisito parcial para a obtenção do título de Mestre em Psicologia Clínica do Centro de Teologia e Ciências Humanas da PUC-Rio.

Orientadora: Profa. Carolina Lampreia 


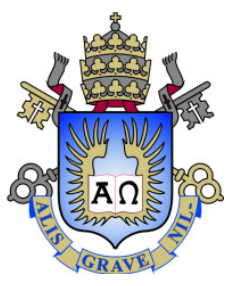

Bruno Costa Larrubia

\title{
A noção de consciência: ecos do cartesianismo e uma crítica a partir da Pragmática
}

\begin{abstract}
Dissertação apresentada como requisito parcial para obtenção do grau de Mestre pelo Programa de Pós-Graduação em Psicologia Clínica do Departamento de Psicologia do Centro de Teologia e Ciências Humanas da PUC-Rio. Aprovada pela Comissão Examinadora abaixo assinada.
\end{abstract}

\section{Profa. Carolina Lampreia}

Orientadora

Departamento de Psicologia - PUC-Rio

Profa. Flavia Sollero de Campos

Departamento de Psicologia - PUC-Rio

Profa. Claudia Passos Ferreira

IMS - UERJ

Profa. Denise Berruezo Portinari Coordenadora Setorial de Pós-Graduação

e Pesquisa do Centro de Teologia

e Ciências Humanas - PUC-Rio

Rio de Janeiro, 12 de janeiro de 2012. 
Todos os direitos reservados. É proibida a reprodução total ou parcial do trabalho, sem autorização da universidade, do autor ou da orientadora.

\section{Bruno Costa Larrubia}

Graduou-se em Psicologia na PUC-Rio (Pontifícia Universidade Católica do Rio de Janeiro) em 2008. Obteve dois prêmios de destaque em Iniciação Científica pela PUC-Rio (2006 e 2008). É especialista em Filosofia Medieval pela Faculdade São Bento do Rio de Janeiro - 2009.

Ficha Catalográfica

Larrubia, Bruno Costa

A noção de consciência: ecos do cartesianismo e uma crítica a partir da Pragmática / Bruno Costa Larrubia; orientadora: Carolina Lampreia. - 2012.

$93 \mathrm{f.} ; 30 \mathrm{~cm}$

1. Dissertação (mestrado) - Pontifícia Universidade Católica do Rio de Janeiro, Departamento de Psicologia, 2012.

Inclui bibliografia

1. Psicologia - Teses. 2. Consciência. 3. Objetivismo. $4 . \quad$ Construtivismo. 5. Representacionalismo. 6. Pragmática 7. Wittgenstein, Ludwig. 8. Descartes, René. I. Lampreia, Carolina. II. Pontifícia Universidade Católica do Rio de Janeiro. Departamento de Psicologia. III. Título. 


\section{Agradecimentos}

A Deus pelo dom da vida e pela oportunidade de realizar meus sonhos.

À minha família, pelo apoio incondicional.

À minha orientadora, $\operatorname{prof}^{\mathrm{a}}$. Carolina Lampreia, pela dedicação e diálogo.

À CAPESe a PUC-Rio, pelo auxílio concedido, sem o qual o trabalho não poderia ter sido realizado.

Aos funcionários do departamento pela presteza e simpatia.

Ao amigo Fabiano, por tornar a atividade intelectual menos solitária.

À Maria Luisa, pelo companheirismo e paciência, sem os quais... 


\section{Resumo}

Larrubia, Bruno Costa; Lampreia, Carolina (Orientadora). A noção de consciência: ecos do cartesianismo e uma crítica a partir da Pragmática. Rio de Janeiro, 2012. 93p. Dissertação de Mestrado em Psicologia Clínica - Departamento de Psicologia, Pontifícia Universidade do Rio de Janeiro.

A noção de consciência pode se apoiar em duas diferentes visões de realidade e de linguagem: a visão objetivista e a construtivista de realidade que adotam, respectivamente, uma visão representacional e pragmática de linguagem. Os projetos filosóficos de Descartes e de Wittgenstein representam exemplos emblemáticos desse debate. No presente trabalho serão expostas as raízes históricas e conceituais que fomentaram o surgimento de duas noções opostas de consciência. Serão examinadas as teorias de Crick, Searle e Edelman, estudiosos que tentaram definir objetivamente a consciência. As críticas propostas por Wittgenstein serão aplicadas às teorias dos autores selecionados na tentativa de extrair implicações desta discussão para o campo da Psicologia.

\section{Palavras-chave}

Consciência; objetivismo; construtivismo; representacionalismo; pragmática; Wittgenstein; Descartes. 


\section{Abstract}

Larrubia, Bruno Costa; Lampreia, Carolina (Advisor). The notion of consciousness: cartesianism echoes and critique from the Pragmatic. Rio de Janeiro, 2012. 93p. MSc. Dissertation- Departamento de Psicologia. Pontifícia Universidade do Rio de Janeiro.

The notion of consciousness can rely on two different views of reality and language: the objectivist and constructivist views of reality that adopt, respectively, a representational and a pragmatic view of language. The philosophical projects of Descartes and Wittgenstein represent key examples of this debate. The present work will present the historical and conceptual roots that encouraged the emergence of two opposing concepts of consciousness. The theories of Crick, and Edelman Searle, scholars who attempted to objectively define consciousness will be examined. And criticisms put forward by Wittgenstein will be applied to these theories in an attempt to draw implications of this discussion to the field of Psychology.

\section{Keywords}

Consciousness; objectivism; constructivism; representacionism; pragmatic; Wittgenstein; Descartes. 


\section{Sumário}

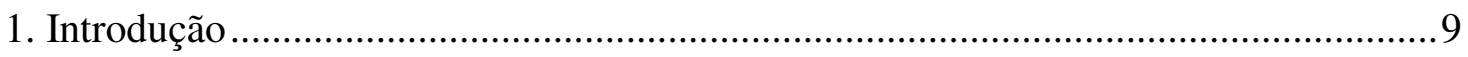

2. Raízes históricas do conceito de consciência contemporâneo.................................... 13

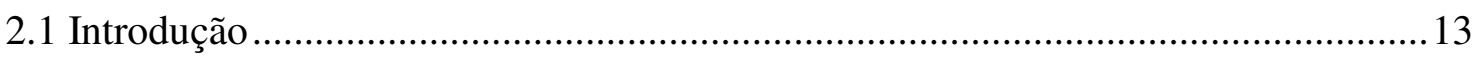

2.2 A visão objetivista de realidade e representacional de linguagem .......................... 15

2.3 A visão construtivista de realidade e pragmática de linguagem...............................21

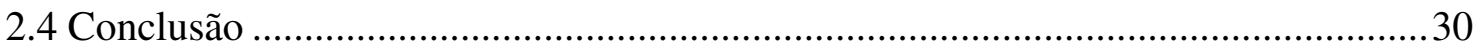

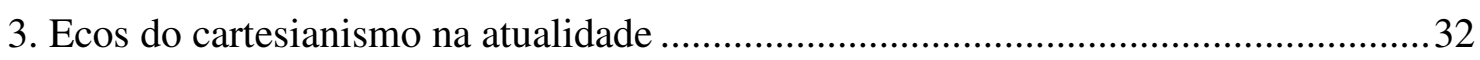

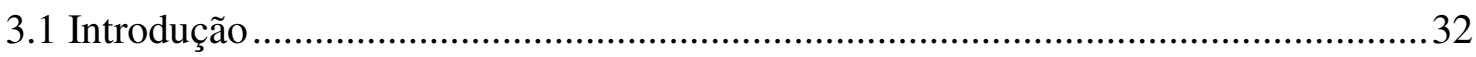

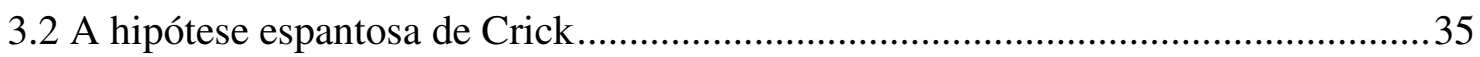

3.3 O naturalismo biológico de Searle.................................................................. 41

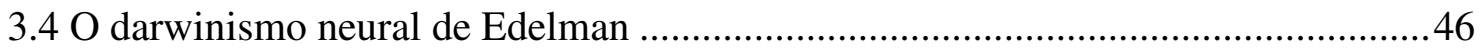

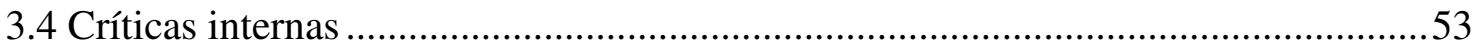

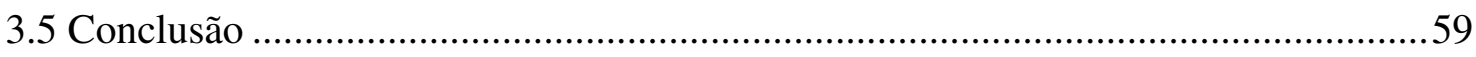

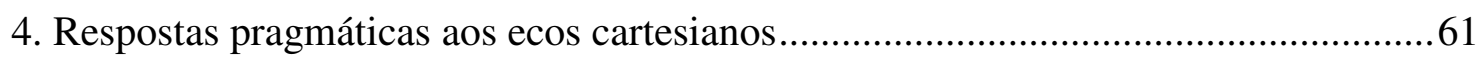

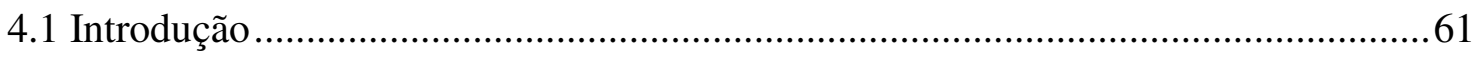

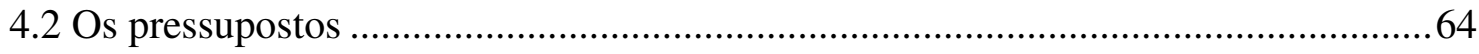

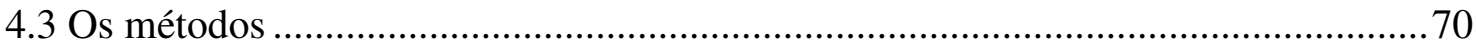

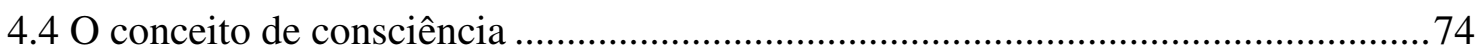

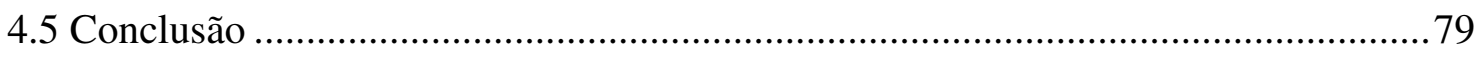

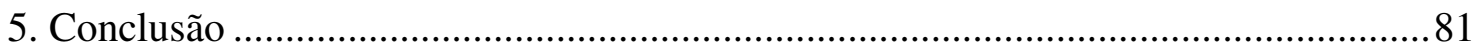

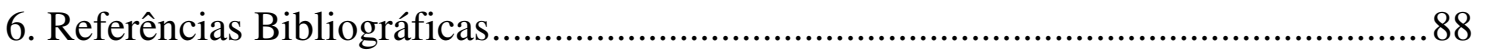


Na paisagem do rio

difícil é saber

onde começa o rio;

onde a lama

começa do rio;

onde a terra

começa da lama;

onde o homem,

onde a pele

começa da lama;

onde começa o homem

naquele homem.

Fragmento de $\mathbf{O}$ cão sem plumas.

João Cabral de Melo Neto, 1950. 